\title{
High serotonin levels due to the presence of the acanthocephalan Hexaglandula corynosoma could promote changes in behavior of the fiddler crab Uca spinicarpa
}

\author{
Ruth A. Pérez-Campos ${ }^{1}$, Rossanna Rodríguez-Canul ${ }^{1, *}$, Juan A. Pérez-Vega ${ }^{1}$, \\ Carlos González-Salas ${ }^{2}$, Sergio Guillén-Hernández ${ }^{2}$

\begin{abstract}
${ }^{1}$ Laboratorio de Inmunología y Biología Molecular, Centro de Investigación y de Estudios Avanzados del Instituto Km. 15.5, carretera Mérida-Xmatkuil, A.P. 4-116 Itzimná, CP 97100, Mérida, Yucatán, México
\end{abstract} \\ Politécnico Nacional-Unidad Mérida. Km. 6 Antigua Carretera a Progreso, CORDEMEX, Mérida, Yucatán, 97310 México \\ ${ }^{2}$ Departamento de Biología Marina, Campus de Ciencias Biológicas y Agropecuarias. Universidad Autónoma de Yucatán,
}

\begin{abstract}
Between February and June 2010, 113 fiddler crabs Uca spinicarpa were collected from the Chuburna lagoon system on the northern coast of the Yucatan Peninsula, México. Of the 68 crabs gathered outside their burrows, 13 were infected with 25 cystacanths of Hexaglandula corynosoma (intensity of infection from 1 to 5) and the remaining 55 crabs were uninfected. The other 45 crabs were found inside their burrows and only one was found infected with 1 cystacanth of $H$. corynosoma. Serotonin (5-HT) levels were higher in the group of crabs infected with $H$. corynosoma in contrast to the group of uninfected crabs and the group of those infected with other parasites. A redundancy analysis corroborated a positive relationship between 5-HT and the intensity of infection with $H$. corynosoma. In contrast, dopamine levels remained similar among different groups of crabs.
\end{abstract}

KEY WORDS: Hexaglandula corynosoma $\cdot$ Uca spinicarpa $\cdot$ Serotonin $\cdot$ Dopamine $\cdot$ Behavioral change Resale or republication not permitted without written consent of the publisher

\section{INTRODUCTION}

Acanthocephalans have the ability to alter the physiology and behavior of their intermediate hosts by increasing the host's vulnerability to predation and thus ensure their transmission to their definitive host (Bollache et al. 2001). It has been shown that larval stages of acanthocephalans, either in the form of metacercariae encysted in the nervous system and/or cystacanths found freely in the hemocele, could promote variations in the neuroendocrine system by increasing the levels of biogenic amines such as serotonin (5-HT) and dopamine (DA) in crabs. This sort of biochemical control could modify specific aspects of the behavior of the host to ensure the permanence of the parasites in an environment where predation can be easily achieved by the definitive host, to complete their life cycle (Helluy \& Holmes 1990, Maynard et al. 1996).

In particular, fiddler crabs Uca spinicarpa collected from the Yucatan Peninsula, México, harbor cystacanths of the acanthocephalan Hexaglandula corynosoma (Guillén-Hernández et al. 2008). In a preliminary study, the intensity of infection of $H$. corynosoma cystacanths was higher in crabs collected outside their burrows than from those collected inside their burrows, and it was suggested an association exists between the intensity of infection 
of these parasites and the modification of a crab's behavior by the alteration of its ability to escape and hide in response to an external disturbance (PérezCampos 2008).

That preliminary study also showed that infected animals remained outside their burrows for longer periods than did the non-parasitized organisms. However, the biochemical mechanisms involved with any changes in behavior in infected crabs were unclear. Thus, in this study we evaluated the putative effect of Hexaglandula corynosoma on the variation of 5-HT and DA levels on the fiddler crab Uca spinicarpa.

\section{MATERIALS AND METHODS}

\section{Sampling}

Fiddler crabs were collected by hand from the Chuburna lagoon system located on the northeast of the Yucatan Peninsula $\left(21^{\circ} 17^{\prime} \mathrm{N}, 8^{\circ} 40^{\prime} \mathrm{W}\right)$. Specimens were placed in plastic containers labeled as collected from either 'inside' or 'outside' their burrows and transported alive with water from the sampling area (salinity, 35-38) and maintained for a maximum period of $5 \mathrm{~d}$ in the laboratory.

\section{Hemolymph sample collection}

Prior to the hemolymph sample collection, crabs were placed for $5 \mathrm{~min}$ in a cold bath $\left(5^{\circ} \mathrm{C}\right)$ to reduce their metabolic activity and to minimize potential handling effects. Then, $700 \mu$ l of hemolymph was extracted from the cavity between the first and the second pair of pleopods of each crab, by using a disposable plastic syringe ( $1 \mathrm{ml}$ ultra-thin gauge needle) impregnated with cold $\left(2\right.$ to $8^{\circ} \mathrm{C}$ ) $10 \%$ sodium citrate (pH 7.0) (modified from Vargas-Albores et al. 1993). Hemolymph samples were placed individually in a $1.5 \mathrm{ml}$ microcentrifuge tube labeled with the identification number of each specimen.

\section{DA concentration}

For the quantitative determination of DA in plasma, a competitive enzyme immunoassay (ELISA) was performed following the protocol described by Alpco Diagnostics in a microtiter plate format. DA was extracted by using a cis-diol-specific affinity gel, acylated and then derivatized enzymatically.
Briefly, $20 \mu \mathrm{l}$ of standards or controls (plus $500 \mu \mathrm{l}$ of deionized water) and $600 \mu \mathrm{l}$ of plasma samples were placed into individual wells of an extraction plate; this was followed by $50 \mu \mathrm{l}$ of assay buffer and $50 \mu \mathrm{l}$ of extraction buffer. The plate was covered with adhesive foil and incubated for $30 \mathrm{~min}$ at room temperature (RT, 20 to $25^{\circ} \mathrm{C}$ ) on a shaker. Then, the plate was washed twice with $1 \mathrm{ml}$ of washing buffer at intervals of $5 \mathrm{~min}$ and dried by tapping the inverted plate on paper towels. Then, $150 \mu$ l of the acylation buffer and $25 \mu$ of acylation reagent were added to each well and incubated for $15 \mathrm{~min}$ on the shaker as before. The plate was then rinsed twice as before. Then $200 \mu \mathrm{l}$ of hydrochloric acid were placed into each well and the plate was incubated for $10 \mathrm{~min}$ at RT on a shaker.

In another ELISA plate, bound with DA antigen, $100 \mu \mathrm{l}$ of standards, controls and samples were each placed in their appropriate wells and incubated for $30 \mathrm{~min}$ on a shaker. After that, $50 \mu \mathrm{l}$ of DA antiserum (anti-rabbit IgG) were placed in the wells, and the plate was covered with adhesive foil and incubated for $2 \mathrm{~h}$ on a shaker. The contents were discarded and the plate was washed 3 times with $300 \mu$ of washing buffer as described above. Then $100 \mu$ of an antirabbit IgG-peroxidase conjugate were placed in each well and incubated for $30 \mathrm{~min}$ on the shaker. The contents were washed and discarded 3 times as described above with $300 \mu$ l of washing buffer. Then $100 \mu \mathrm{l}$ of 3,3',5,5'-tetramethylbenzidine (TMB) substrate were added to each well and the wells were incubated for $30 \mathrm{~min}$ on the shaker, avoiding exposure to direct sunlight. Finally, $100 \mu \mathrm{l}$ of the stopping solution were added to each well. After $10 \mathrm{~min}$, the optical density was measured at $450 \mathrm{~nm}$ (650 nm reference wavelength). Quantification of known samples (as $\mu \mathrm{g} \mathrm{ml}^{-1}$ ) was determined by comparing their absorbance with a reference curve prepared with known standard concentrations.

\section{5-HT concentration}

Concentrations of 5-HT were detected in an ELISA format modified from the protocol described by Alpco Diagnostics. In the first step, 5-HT is quantitatively acylated. The subsequent competitive ELISA kit uses the microtiter plate format.

Briefly, $25 \mu \mathrm{l}$ of standards, controls and plasma samples were placed in microcentrifuge tubes with $500 \mu \mathrm{l}$ of acylation buffer and $25 \mu \mathrm{l}$ of acylation reagent, mixed on a vortexer and incubated for $15 \mathrm{~min}$ at RT. Then, $100 \mu \mathrm{l}$ of standards, controls and 
samples were each placed in their respective wells in the ELISA microplate coated with 5-HT antigen. The plate was covered with adhesive foil and incubated for $30 \mathrm{~min}$ at RT on a shaker (600 rpm). The plate was then washed 3 times with $300 \mu \mathrm{l}$ of washing buffer at intervals of 5 min each and dried by tapping the inverted plate on paper towels. Then, $25 \mu \mathrm{l}$ of 5-HT antiserum (anti-rabbit IgG) were placed in each well and the plate was incubated for $2 \mathrm{~h}$ on the shaker. The contents were discarded and wells washed 3 times with $300 \mu$ l of washing buffer as described above. Then, $100 \mu \mathrm{l}$ of the anti-rabbit IgG-peroxidase conjugate were placed in each well and the plate was incubated for $15 \mathrm{~min}$ on the shaker. The plate was washed as above with $300 \mu$ of washing buffer and $100 \mu \mathrm{l}$ of the substrate TMB was added to each well. The plate was incubated for $30 \mathrm{~min}$ on the shaker avoiding exposure to direct sunlight. Finally, $100 \mu \mathrm{l}$ of the stopping solution were added to each well. After $10 \mathrm{~min}$, the optical density was measured at $450 \mathrm{~nm}$ (650 nm reference wavelength). Quantification of known samples (as $\mu \mathrm{g} \mathrm{ml}^{-1}$ ) was achieved by comparing their absorbance with a reference curve prepared with known standard concentrations.

\section{Parasite load}

Before the parasitological evaluations, the length and width of the cephalothorax of each crab was measured with digital vernier calipers. Crabs were separated into 3 size categories based on the cephalothorax width: (1) small (12.0 to $15.9 \mathrm{~mm})$, (2) medium (16.0 to $19.9 \mathrm{~mm}$ ) and (3) large (20.0 to $23.9 \mathrm{~mm}$ ). The sex of each crab was also determined (Pérez-Campos 2008).

The digestive gland was rinsed with $7 \%$ saline solution, squashed between two $10 \times 10 \mathrm{~cm}$ glass plates $(0.05 \mathrm{~cm}$ thick) and examined at $4 \times$ and $40 \times$ for cystacants, which were removed and initially placed in Petri dishes with $7 \%$ saline solution. After $15 \mathrm{~min}$, they were placed in vials, each containing $3 \mathrm{ml}$ of distilled water, and held at $4^{\circ} \mathrm{C}$ for $24 \mathrm{~h}$ to facilitate eversion of their proboscises, and then they were preserved in $70 \%$ alcohol. Parasite species identification was performed according to Amin (1985), Nickol et al. (2002) and Guillén-Hernández et al. (2008). Finally, a database containing different groups according to parasite infection was developed: Group 1: crabs infected only with Hexaglandula corynosoma; Group 2: heterologous infection (crabs infected with other parasites); Group 3: noninfected crabs.
Infection variables for each species of parasite such as prevalence, mean abundance and mean intensity were calculated (Bush et al. 1997). Infection intensity (number of cystacanths per host) of Hexaglandula corynosoma was determined using 4 categories according to the number of parasites found in crabs: (1) zero intensity $(0$, uninfected); (2) low intensity (1 cystacanth); (3) medium intensity (2 to 3 cystacanths); (4) high intensity (4 to 5 cystacanths).

\section{Data analysis}

The non-parametric $\chi^{2}(2 \times 2)$ analysis was used to determine whether there were significant differences $(\alpha<0.05)$ between the proportion of infected individuals along with their 5-HT values in crabs from outside and inside their burrows (Zolman 1993). The non-parametric Kruskal-Wallis analysis was used to determine whether there were significant differences $(\alpha<0.05)$ between categories (Zolman 1993). The relationship between Hexaglandula corynosoma infection intensity and the content levels of DA and 5-HT was analyzed using a redundancy analysis (RDA) (Leps \& Smilauer 2003). A Monte Carlo analysis with 999 permutations was carried out to select the variables included in the RDA in order to determine associations between physiological and infection parameters (significance of canonical axes).

\section{RESULTS}

\section{Parasite description}

The acanthocephalan species found in Uca spinicarpa was identified as Hexaglandula corynosoma. Many of the diagnostic characteristics such as the presence of a cylindrical proboscis armed with 16 longitudinal rows of 11 to 12 hooks each were in accordance with their original descriptions (Amin 1985, Nickol et al. 2002, Guillén-Hernández et al. 2008).

\section{Parasitic infection levels.}

Of the 68 Uca spinicarpa that were collected outside their burrows, 13 crabs were parasitized with 25 cystacanths of Hexaglandula corynosoma (infection intensity from 1 to 5 cystacanths per crab), and 45 were uninfected. Only $1 \mathrm{crab}$ out of 45 collected from inside their burrows harbored just 1 cystacanth. Only sexually well-developed cystacanths were found in 
crabs collected outside their burrows. With regard to size of the crabs, all 16 of the small-sized crabs (Group 1) were negative for the presence of cystacanths, 9 medium-sized crabs (Group 2, $\mathrm{n}=68$ ) were infected with 17 cystacanths and 5 large-sized crabs (Group 3) harbored 9 cystacanths. Of the 104 male crabs collected 12 were infected with 21 cystacanths, and of the 9 female crabs collected 2 were infected with 5 cystacanths (Table 1).

\section{DA and 5-HT concentrations}

No differences were found between DA concentrations of crabs infected with Hexaglandula corynosoma, crabs infected with other parasites (heterologous) and non-parasitized crabs $(H=2.09, \mathrm{p}=$ $0.3427)$. But significant differences were observed in 5-HT contents in crabs infected with $H$. corynosoma ( $H=6.59, \mathrm{p}=0.0019)$ among the other 2 groups (Table 2, Fig. 1).

Similarly, statistical differences were found by comparing the proportion of infected crabs (high 5 -HT values) gathered from outside their burrows (13 out of $68 \mathrm{crabs}$ ) to those found inside their burrows ( 1 out of 45 crabs) $\left(\chi^{2}=7.69 ; p=0.0076\right.$; Fig. 1 ).

The DA and 5-HT concentrations in the crabs with respect to sex (DA: $H=1.84, \mathrm{p}=0.1701 ; 5-\mathrm{HT}: H=$ $0.01, \mathrm{p}=0.9114$ ) and cephalothorax size (DA: $H=$ $0.89, \mathrm{p}=0.633 ; 5-\mathrm{HT}: H=0.97, \mathrm{p}=0.3984$ ) are summarized in Table 2.

Regarding to the infection intensity (no. of cystacanths per host) of Hexaglandula corynosoma, only $39 \%$ of the variability was explained through the RDA. The physiological variable that explained the consecutive variance was 5 -HT. The infection intensity of $H$. corynosoma was positively related with axis number 1, According to the RDA, high 5-HT levels were strongly associated with the medium ( 2 to 3 cys-

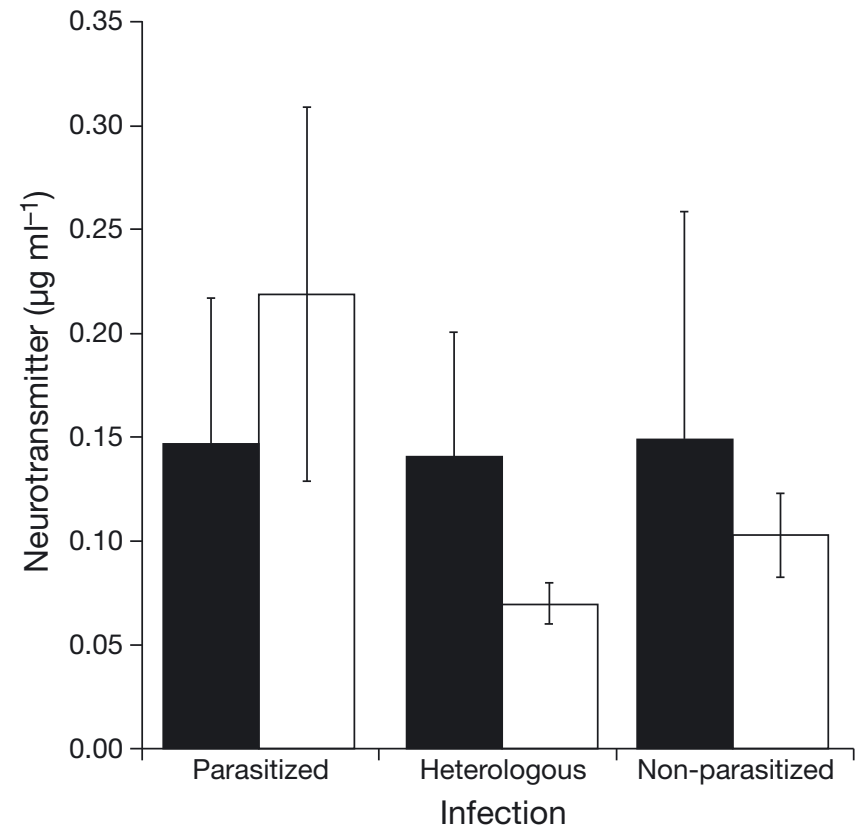

Fig. 1. Uca spinicarpa. Mean dopamine (DA, black bars) and serotonin (5-HT, open bars) concentrations $( \pm \mathrm{SD})$ in hemolymph among fiddler crabs infected with the acanthocephalan Hexaglandula corynosoma, other parasites (heterologous) and non-parasitized organisms

tacanths per host) and high (4 to 5 cystacanths per host) intensity of infection (Fig. 2).

\section{DISCUSSION}

5-HT and other monoamines have been associated with behavioral modulation in vertebrates and invertebrates owing to its specific roles in synaptic transmission inducing changes in the activity of neurons. At the molecular level, 5-HT influences the modulation of ion channels, protein synthesis and enzymatic activity (Livingstone et al. 1980, Walker et al. 1996,

Table 1. Uca spinicarpa. Numbers of examined and parasitized hosts and cystacanths (n), prevalence (percentage of hosts parasitized), frequency of occurrence in all hosts examined and mean intensity of infection in the parasitized hosts in fiddler crabs infected with the acanthocephalan Hexaglandula corynosoma among samples collected in the Chuburna lagoon system, Yucatan Peninsula

\begin{tabular}{|c|c|c|c|c|c|c|c|}
\hline \multirow[t]{2}{*}{ Classification criteria } & \multicolumn{2}{|c|}{ Position in relation to the burrow } & \multicolumn{2}{|c|}{ Sex } & \multicolumn{3}{|c|}{ Cephalothorax size } \\
\hline & Outside & Inside & Male & Female & Small & Medium & Large \\
\hline Examined hosts (n) & 68 & 45 & 104 & 9 & 16 & 69 & 28 \\
\hline Parasitized hosts (n) & 13 & 1 & 12 & 2 & 0 & 9 & 5 \\
\hline Cystacanths (n) & 25 & 1 & 21 & 5 & 0 & 17 & 9 \\
\hline Prevalence (\%) & 19.1 & 2.2 & 11.5 & 22.2 & 0 & 13.0 & 17.8 \\
\hline Mean frequency & 0.36 & 0.02 & 0.20 & 0.55 & 0 & 0.27 & 0.32 \\
\hline Mean intensity & 1.92 & 1 & 1.75 & 2.5 & 0 & 2.11 & 1.8 \\
\hline
\end{tabular}


Table 2. Uca spinicarpa. Non-parametric Kruskall-Wallis analysis of the effect of DA and 5-HT levels in the hemolymph of fiddler crab between samples collected from crabs outside and inside their burrows, size and sex of crabs and the infection effect by the acanthocephalan $H$. corynosoma. Significant differences among samples of each classification criteria are shown in bold $(\alpha \leq 0.05)$

\begin{tabular}{|c|c|c|c|c|c|c|c|c|c|}
\hline \multirow{2}{*}{$\begin{array}{l}\text { Classification } \\
\text { criteria }\end{array}$} & \multirow[t]{2}{*}{$\mathrm{n}$} & \multicolumn{4}{|c|}{ DA content $\left(\mu \mathrm{g} \mathrm{ml}^{-1}\right)$} & \multicolumn{4}{|c|}{ 5-HT content $\left(\mu \mathrm{g} \mathrm{ml}^{-1}\right)$} \\
\hline & & Mean \pm SD & $H$ & $\mathrm{df}$ & $\mathrm{p}$-value & Mean $\pm \mathrm{SD}$ & $H$ & df & $\mathrm{p}$-value \\
\hline \multicolumn{10}{|l|}{ Sex } \\
\hline Male & 9 & $0.149 \pm 0.10$ & 1.84 & 1,1 & 0.1701 & $0.017 \pm 0.08$ & 0.01 & 1,1 & 0.9114 \\
\hline Female & 104 & $0.121 \pm 0.09$ & & & & $0.122 \pm 0.25$ & & & \\
\hline \multicolumn{10}{|l|}{ Size } \\
\hline Small & 16 & $0.151 \pm 0.10$ & 0.89 & 1,2 & 0.633 & $0.041 \pm 0.15$ & 0.97 & 1,2 & 0.3984 \\
\hline Medium & 69 & $0.149 \pm 0.08$ & & & & $0.015 \pm 0.07$ & & & \\
\hline Large & 28 & $0.138 \pm 0.12$ & & & & $0.046 \pm 0.16$ & & & \\
\hline \multicolumn{10}{|l|}{ Infection } \\
\hline Parasitized & 14 & $0.147 \pm 0.07$ & 2.09 & 1,2 & 0.3427 & $0.219 \pm 0.09$ & 6.59 & 1,2 & 0.0019 \\
\hline Heterologous & 27 & $0.141 \pm 0.06$ & & & & $0.070 \pm 0.01$ & & & \\
\hline Non-parasitized & 72 & $0.149 \pm 0.11$ & & & & $0.103 \pm 0.02$ & & & \\
\hline
\end{tabular}

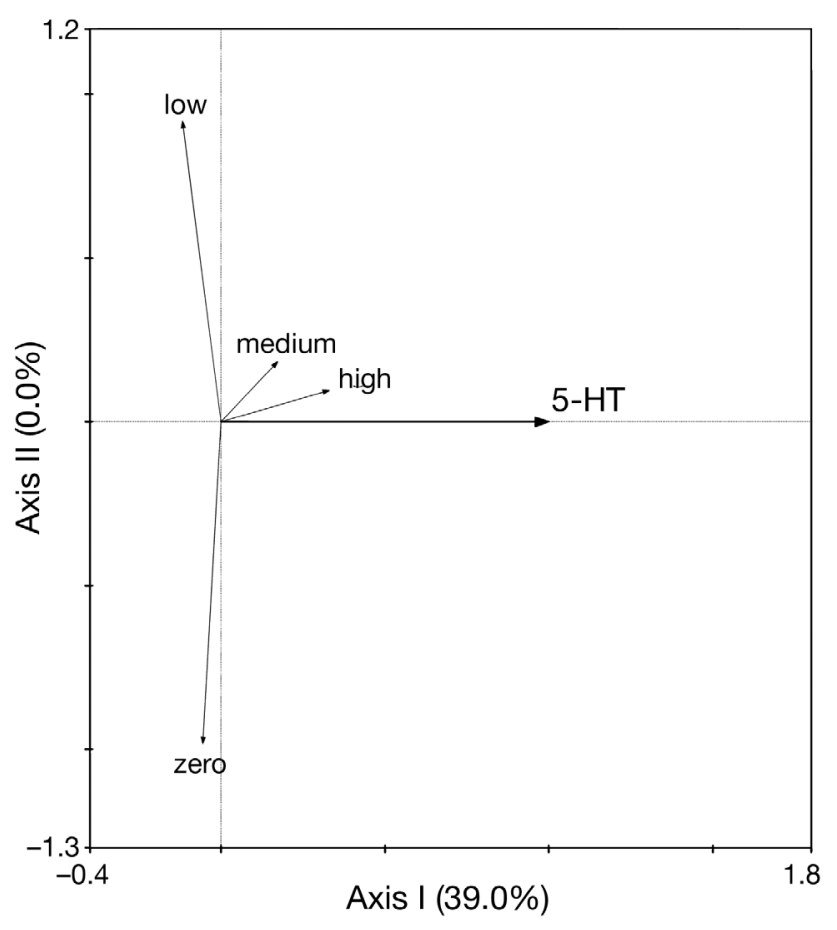

Fig. 2. Uca spinicarpa. Redundancy analysis (RDA) of the 5 -HT concentration in hemolymph (explanatory variable) and the infection intensity (response variable) in fiddler crabs. The significance values of the axes are shown in parentheses ( $p=0.028$, with 999 permutations)

Libersat \& Pflueger 2004). There is evidence that the release of specific neuromodulators activates specific neuronal circuits that underlie particular behaviors; therefore, it has been suggested that behavior per se is the result of a coordinated action of monoamines (Sombati \& Hoyle 1984).
In a previous study, differences in infection variables in fiddler crabs collected inside and outside their burrows suggested that the acanthocephalan Hexaglandula corynosoma alters the behavior of the crabs, as they were unable to escape from an external disturbance (Pérez-Campos 2008). We also hypothesize that some neuromodulators such as 5-HT and DA could be involved in this behavioral pattern. Results from this study showed that fiddler crabs collected from outside their burrows had the highest intensity of infection with $H$. corynosoma and the 5-HT levels were also higher.

In other host-parasite systems it has been well documented that the presence of the parasite would 'manipulate' or alter the behavior of the host by increasing the intermediate host's time of exposure to predation by the definitive host in order to complete the life cycle (Moore 1984, Latham \& Poulin 2002).

In the present study, highest infection levels were found in medium-sized crabs. According to Poulin (2000), cumulative rates of parasitization are given in terms of age and thus the size of the hosts; parasites that induce intermediate host mortality weaken the relationship between the size and intensity of infection by removing larger hosts that have a greater accumulation of parasites from the population. According to this, medium-sized crabs from this study could be more exposed to infection because at this stage they are reaching sexual maturity and they need to complete their reproductive phase, so they could spend more time outside their burrows to search and compete for mates; small-sized crabs do not yet show this kind of pattern. On the other hand, large-sized crabs do not need to seek or to compete 
for sexual partners, so their exposure to infection could be more limited when compared with that of the medium-sized crabs.

Another interesting observation in this study is that we were able to corroborate that only cystacanths that were sexually well developed were found in crabs collected from outside their burrows (PérezCampos 2008). In the RDA, 5-HT is the only variable that increases as infection intensity increases (Fig. 2). The intensity of infection of a given parasite is an important factor that can be considered during the behavioral change of their host (Latham \& Poulin 2002). The effect that a single cystacanth can achieve is not similar to that produced by a group of them because the production of 5-HT by the host increases as the number of cystacanths increase. Acantocephalans are dioecious organisms and male and female parasites need to be present inside their definitive host during the right time of their reproductive cycle to continue their life cycle (Schmidt 1985). The definitive host has a greater chance of being infected with both male and female acanthocephalans if it ingests intermediate hosts with high numbers of cystacanths. The RDA indicates that Hexaglandula corynosoma has found a mechanism to increase the number of cystacanths that are able to release enough 5-HT to modify the behavior of Uca spinicarpa. 5-HT levels were higher in parasitized U. spinicarpa, and significant differences were observed in crabs found outside their burrows.

With regard to DA, the values remained constant among all analyzed crabs. The timing of the decision to withdraw from an encounter is a key element in theoretical models of fighting games for individuals and their perception of danger (Maynard-Smith 1982). In this sense, the possibility arises that this kind of decision-making process may be influenced by a change in the balance between 5 -HT and levels of other neuromodulators such as DA; therefore, if this balance is affected by an increase in 5-HT levels while DA levels remain constant a change in the behavior can occur in the host as was observed in the present study. Previous studies have shown that an increase in 5-HT levels may modify the 'normal retirement or hiding behavior' of parasitized crabs to a 'willingness to fight' or to become aggressive (Huber et al. 1997).

In summary, results from this study suggest that Uca spinicarpa specimens infected with Hexaglandula corynosoma have increased levels of 5-HT in the hemolymph. This could cause a behavioral change in crabs that could delay their response to escaping or hiding, making them more vulnerable to predation by the definitive host. This is the first preliminary report showing an increase of 5-HT levels in fiddler crabs infected with $H$. corynosoma. These results are encouraging as this is the first report that may help explain the behavioral change of fiddler crabs in the tropics. However, a more comprehensive study with a larger sample sizes of crabs collected during all seasons will help to corroborate our findings.

Acknowledgements. We thank El Consejo Nacional de Ciencia y Tecnología (CONACYT) for providing a postgraduate studentship to R.P.C. (Grant No. 268028). Special thanks are given to Ms. Y. Zapata Varela, G. Hernández Cisneros, T. Ruz Ruiz and H. Villegas Hernández from the CINVESTAVIPN Unidad Merida for their fieldwork assistance, advice and technical support. We also thank Dr. C. Pascual Jimenez for immunological advice. This study was financed by the external services of the Laboratory of Immunology and Molecular Biology from CINVESTAV-IPN Unidad Merida and by a PROMEP grant (no. 103.5/09/1373).

\section{LITERATURE CITED}

Amin OM (1985) Classification. In: Crompton DWT, Nickol BB (eds) Biology of the acanthocephalan. Cambridge University Press, Cambridge, p 27-72

Bollache L, Gambado G, Cézelly F (2001) The effects of two acanthocephalan parasites, Pomphorhynchus laevis and Polymorphus minutus on pairing success in male Gammarus pulex (Crustacea: Amphipoda). Behav Ecol Sociobiol 49:296-303

> Bush AO, Lafferty KD, Lotz JM, Shostak AW (1997) Parasitology meets ecology on its own terms: Margolis et al. revisited. J Parasitol 83:575- 583.

Guillén-Hernández S, García-Varela M, Pérez-Ponce de León G (2008) First record of Hexaglandula corynosoma (Travassos, 1915) Petrochenko, 1958 (Acanthocephala: Polymorphidae) in intermediate and definitive hosts in Mexico. Zootaxa 1873:61-68

Helluy S, Holmes JC (1990) Serotonin, octopame, and the clinging behavior induced by the parasite Polymorphus paradoxus (Acanthocephala) in Gammarus lacustris (Crustacea). Can J Zool 68:1214-1220

Huber R, Smith K, Delago A, Isaksson K, Kravitz EA (1997) Serotonin and aggressive motivation in crustaceans: altering the decision to retreat. Proc Natl Acad Sci USA 94:5939-5942

Latham ADM, Poulin R (2002) Effect of acanthocephalan parasites on hiding behaviour in two species of shore crabs. J Helminthol 76:323-326

Leps J, Smilauer P (2003) Multivariate analysis of ecological data using CANOCO. Cambridge University Press, Cambridge

Libersat F, Pflueger HJ (2004) Monoamines and the orchestration of behavior. Int J Biol Sci 54:17-25

Livingstone MS, Harris-Warrick RM, Kravitz EA (1980) Serotonin and octopamine produce opposite posture in lobsters. Science 208:76-79

Maynard BJ, DeMartini L, Wright WG (1996) Gammarus lacrustris harboring Polymorphus paradoxus show 
altered patterns of serotonin-like immunoreactivity. J Parasitol 82:663-666

Maynard-Smith J (1982) Evolution and the theory of games. Cambridge University Press, Cambridge

Moore J (1984) Altered behavioral responses in intermediate hosts: an acanthocephalan parasite strategy. Am Nat 123:572-577

Nickol BB, Heard RW, Smith NF (2002) Acanthocephalans from crabs in the southeastern U.S., with the first intermediate hosts known for Arhythmorhynchus frassoni and Hexaglandula corynosoma. J Parasitol 88:79-83

Pérez-Campos RA (2008) Comportamiento en el cangrejo violinista, Uca spinicarpa (Rathbun, 1900) infectado por el acantocéfalo Hexaglandula corynosoma (Travassos, 1915) en el sistema lagunar de Chuburná Yucatán, México. Tesis de licenciatura, Universidad Autónoma de Yucatán, Mérida

Poulin R (2000) Variation in the intraspecific relationship

Editorial responsibility: Grant Stentiford,

Weymouth, UK between fish length and intensity of parasitic infection: biological and statistical causes. J Fish Biol 56:123-137

Schmidt GD (1985) Development and life cycles. In: Crompton DWT, Nickol BB (eds) Biology of the acanthocephalan. Cambridge University Press, Cambridge, p 273-305

Sombati S, Hoyle G (1984) Generation of specific behaviors in a locust by local release into neuropil of the natural neuromodulator octopamine. J Neurobiol 15:481-506

> Vargas-Albores F, Guzmán MA, Ochoa JL (1993) An anticoagulant solution for haemolymph collection and prophenoloxidase studies of penaeid shrimp (Penaeus californiensis). Comp Biochem Physiol A Physiol 106: 299-303

Walker RJ, Brooks HL, Holden-Dye L (1996) Evolution and overview of classical transmitter molecules and their receptors. J Parasitol 113(Suppl):32-33

Zolman JF (1993) Biostatistics: experimental design and statistical inference. Oxford University Press, New York, NY

Submitted: September 25, 2011; Accepted: February 8, 2012 Proofs received from author(s): April 26, 2012 